\title{
Cathodoluminescence Microscopy and Spectroscopy of Planar Deformation Features of Shocked Zircon from the Vredefort Impact Structure, South Africa
}

\author{
A. Gucsik \\ Max Planck Institute for Chemistry, Department of Geochemistry, Joh-J.-Becherweg 27. Universitätcampus, Mainz, \\ D-55128, Germany
}

\begin{abstract}
Thorough understanding of the shock metamorphic signatures of zircon will provide a basis for the application of this mineral as a powerful tool for the study of terrestrial impact struetures and formations. This paper of the cathodoluminescence (CL) spectroseopic signatures of naturally shocked zircon erystals from the Vredefort Dome, South Africa contributes to the understanding of the formation of microdeformation in zircon under very high pressures. All investigated shocked samples shows an inverse relationship between the brightness of the backscattered electron (BSE) signal and the corresponding cathodoluminescence intensity of the zonation patterns. The CL spectra of samples are characterised by narrow emission lines and broad bands in the region of visible light and in the near-ultraviolet range. The emission lines result from rare earth element activators and the broad bands are associated with lattice defects. The results show a clear relationship between the CL properties of zircon and shock pressure, which confirm the possible use of these methods as shock indicators.
\end{abstract}

Keywords: shock metamorphism, zircon, terrestrial impact structures, activator elements.

PACS: 78.60. Hk, 87.64.Ee, 91.65. An, 96.25. Pq

\section{INTRODUCTION}

Zircon is a highly refractory and weathering-resistant mineral that has proven useful as an indicator of shock metamorphism in the study of impact structures and formations ([1] and references therein). Zircon has advantages compared to quartz or other shock-metamorphosed rock-forming minerals that have been widely used as impact indicators, but are far less refractory than zircon [2]. Furthermore, $\mathrm{U}-\mathrm{Pb}$ dating of zircon can provide constraints on the ages of impact events or deposition of impact formations [3].

This paper of the cathodoluminescence microscopic and spectroscopic properties of the naturally shocked zircon specimens from the Vredefort (South Africa) impact structure contributes to the understanding of high-pressure microdeformation in zircon. The purpose of this investigation is to further investigate the capability of the SEM-CL technique to document shock deformation and to determine whether specific CL effects in zircon can be utilized to determine particular shock pressure stages. 


\section{METHODOLOGY}

The samples were first examined under a petrographic microscope. Digital optical images were stored without further computer enhancement. Areas of approximately $450 \times 450 \mu \mathrm{m}$ were selected for CL and BSE imaging. Raman spectra were taken from $3 \mu \mathrm{m}^{3}$ sample volume and CL spectra were obtained from approximately $35 \times 45 \mu \mathrm{m}$ areas. The samples were then examined with an Oxford Mono-CL system attached to a JEOL JSM 6400 scanning electron microscope (SEM). Operating conditions for all SEM-CL investigations were $15 \mathrm{kV}$ accelerating voltage and $1.2 \mathrm{nA}$ beam current; backscattered-electron (BSE) and cathodoluminescence (CL) images were obtained. The BSE and CL images were captured digitally. CL spectra were recorded in the wavelength range of $200-800 \mathrm{~nm}$, with $1 \mathrm{~nm}$ resolution. The grating of the monochromator was 1200 lines $/ \mathrm{mm}$.

\section{THE VREDEFORT DOME}

The Vredefort impact structure is located approximately $120 \mathrm{~km}$ SW of Johannesburg in South Africa (Fig. 1). It is situated within Archean and Paleoproterozoic rocks of the Kaapvaal craton. According to the shock-effect spatial distribution, geophysical modelling, and satellite image analyses have demonstrated that its diameter is between $250-300 \mathrm{~km}$. There are several mineralogical and geological evidences to confirm the origin of the Vredefort Structure by hypervelocity impact event at $2.02 \mathrm{Ga}$, including the presence of coesite and stishovite, shatter cones, and planar deformation features in quartz, zircon and feldspar. Moreover, analysis of the Re-Os isotopic system of the Vredefort Granophyre led to the confirmation of this rock type as an impact melt rock ([4-6]-and references therein).

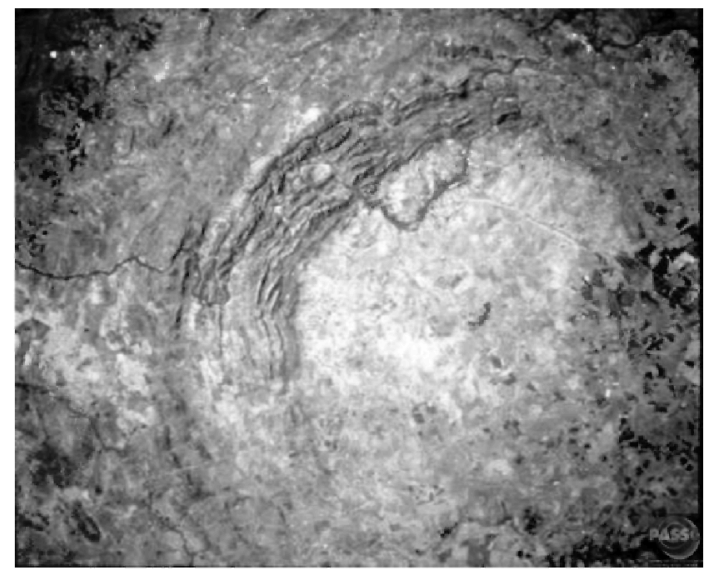

FIGURE 1. A satellite image of the Vredefort Dome, South Africa (Space Shuttle Image STS 51I-33-56AA from Earth Impact Database, 2009) [7] 


\section{RESULTS}

\section{Cathodoluminescence (CL) and Backscattered Electron (BSE) Image Observations}

In general, all of shock-deformed zircon samples from the Vredefort impact structure (in total, 12 grains) are characterized by the presence of low densities of open, wide, and irregularlyshaped fractures. Individual fractures typically have widths between 5 and $13 \mu \mathrm{m}$. Many of these grains display a well-developed growth zonation parallel to the crystal edges. Planar Fractures $(\mathrm{PFs})$ associated with the irregular fracture system are observable in an optical micrograph (Fig. 2a), BSE (Fig. 2b) and CL images (Figs. 2c and d) of zircon grains from the Vredefort impact structures (South Africa). In general, a high density of micro-lamellar feature system occurred in two orientations can be discernible in BSE and CL images showing dark lines (Figs. 3a and b). Some of the grains show an inverse relationship between BSE and CL brightness.

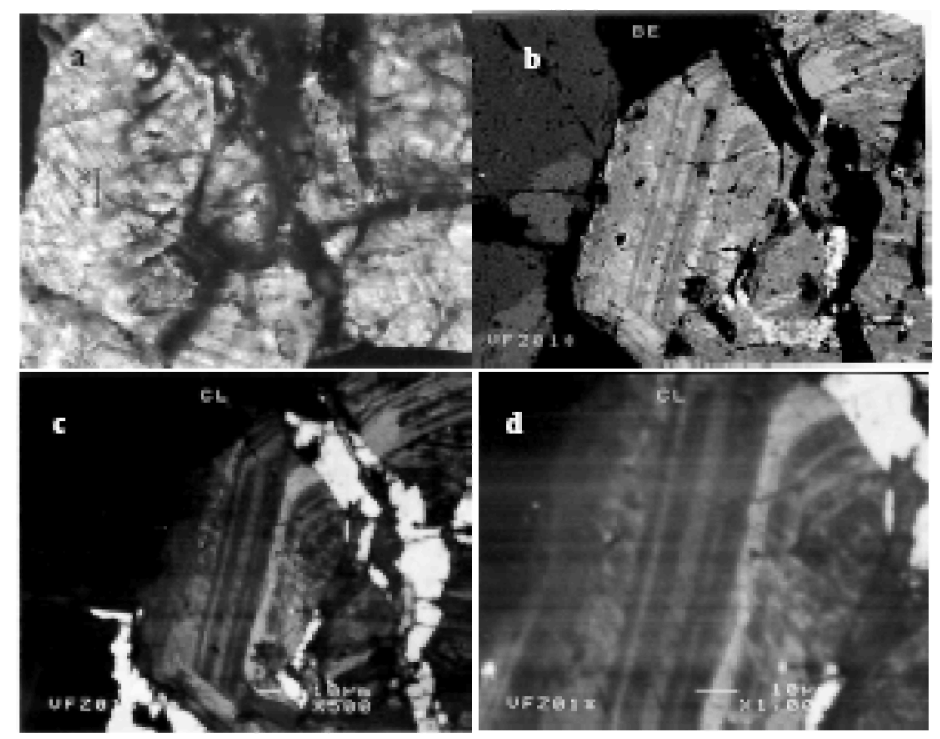

FIGURE 2. Optical microscope (a), BSE (b) and CL (c,d) images of a zircon grain from the Vredefort impact structure (South Africa) showing a planar microstructures, which are also visible in the magnified CL image (d). 

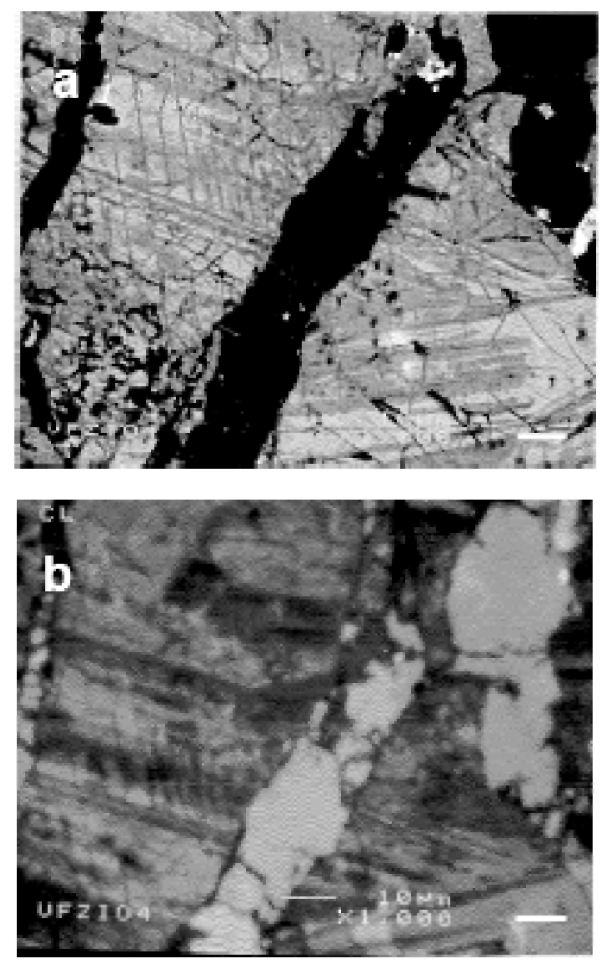

FIGURE 3. BSE (a) and CL (b) images of Planar Deformation Features (PDFs).

\section{Cathodoluminescence (CL) Spectrometry}

Five Vredefort zircon samples were selected for the CL spectroscopical analysis as they were shown in Figures 4a-d. Compared to CL properties of Ries samples, zircon grains from the Vredefort crater exhibit similar CL spectral features as follows. Narrow emission peaks centered at $314,406,475-484,580$, and $628 \mathrm{~nm}$ with relatively high peak intensities are superimposed on a broad band. The doublet peak at 475-484 dominates CL spectra of all samples (Fig. 5). 

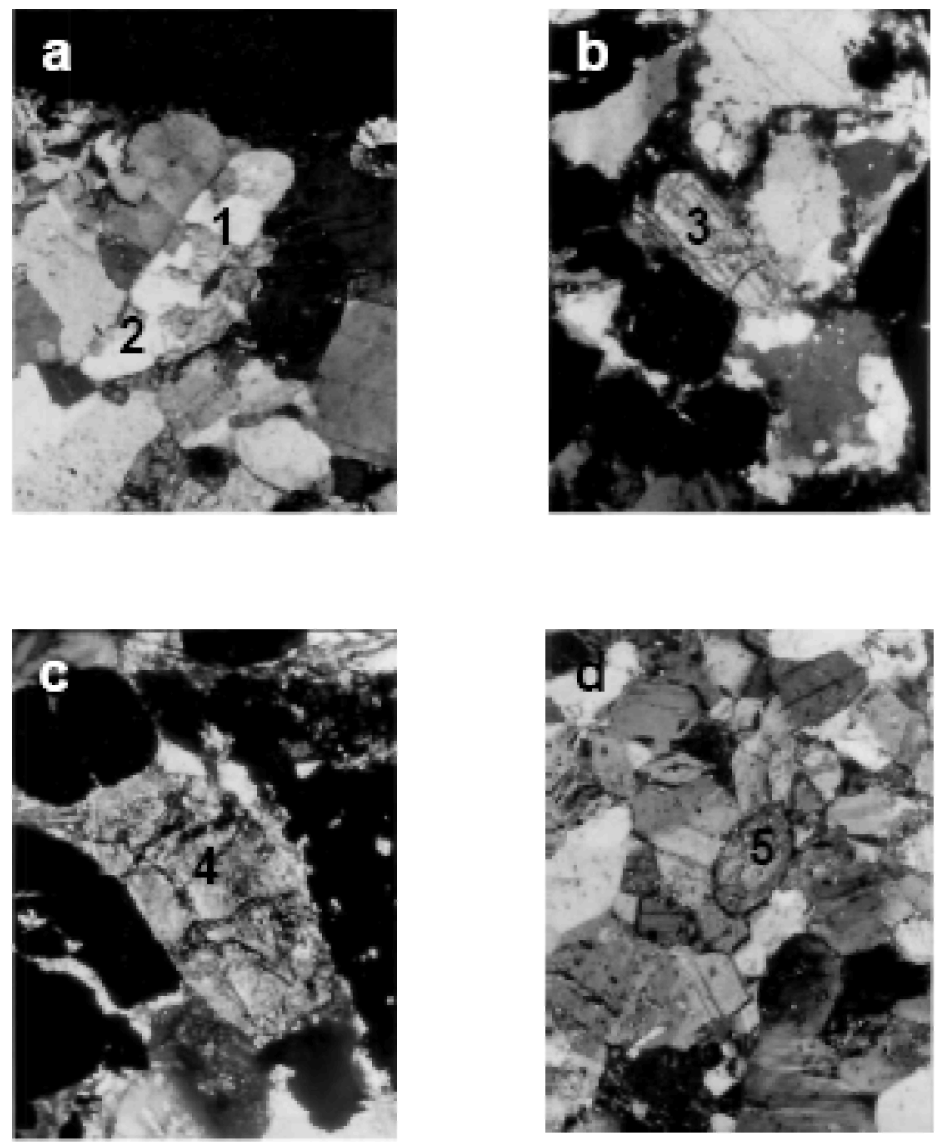

FIGURE 4. Cross-polarized optical micrographs (a-d) of five selected zircon samples (1-5) from the Vredefort impact structure. 


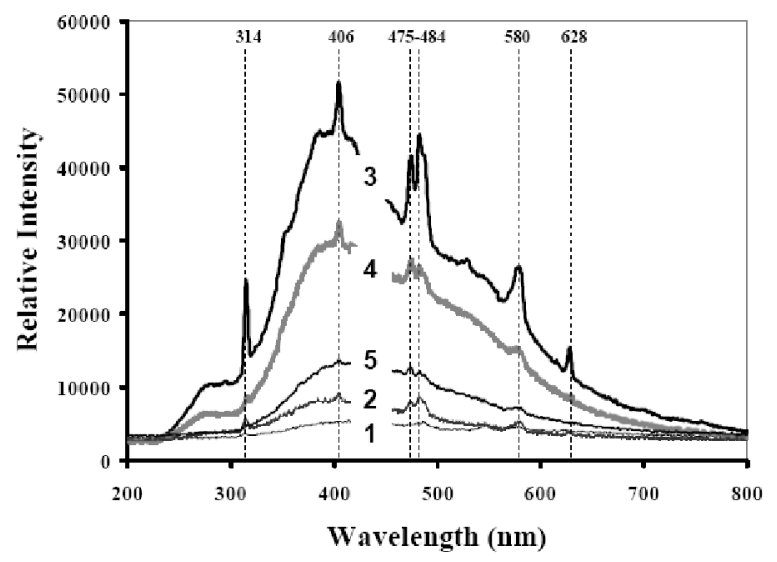

FIGURE 5. Cross-polarized optical micrographs (a-d) of five selected zircon samples (1-5) from the Vredefort impact structure and their cathodoluminescence spectra (e).

\section{DISCUSSION}

\section{The Nature of SEM-CL Properties of Microdeformations of Shocked Zircon Crystals}

The inverse relationship between BSE and CL brightness might be explained as follows. According to Remond et al. [8], backscattered electrons (BSE) are primary beam electrons that leave the specimen as a result of a single large-angle scattering event or multiple small angle scattering processes. The fraction of primary beam electrons, which leave the specimen, $\eta=$ $\mathrm{I}_{\mathrm{BSE}} / \mathrm{I}_{\mathrm{B}}$, increases with the mean atomic number of the specimen, where $\mathrm{I}_{\mathrm{B}}$ is the beam current entering the sample and $\mathrm{I}_{\mathrm{BSE}}$ is the BSE current leaving the specimen. This dependence of backscattered-electron yield on mean atomic number allows for the compositional imaging of flat surfaces with submicrometer resolution, which provides better spatial resolution and microcompositional information than standard optical methods. The BSE contrast is sensitive to changes of average atomic number, i.e., higher $Z$ causes bright BSE yield and lower $Z$ leads to the dark BSE brightness. In the case of natural zircon, the inverse relationship between BSE and $\mathrm{CL}$ brightness might be caused by high concentrations of $\mathrm{Hf}, \mathrm{Y}, \mathrm{Yb}, \mathrm{U}$, and $\mathrm{Th}$, corresponding to high BSE intensities. The CL images of naturally shock-deformed zircon crystals from the Ries and Vredefort impact structures also exhibit an inverse relationship between BSE and CL brightness, which indicates that the spatial distribution or abundance of the above-mentioned elements causes low (dark CL) and high (bright CL) intensities. 


\section{Cathodoluminescence Spectral Features of Shocked Zircon}

The luminescence properties are mostly the result of luminescence-activating ions, such as transition metals, rare-earth elements, or actinides. According to Remond et al. [8] the trivalent rare-earth element (REE) radiative recombination centers are characterized by sharp visible and near-infrared (NIR) emission peaks in the spectrum. The luminescence results from electronic transitions between the partially filled $4 \mathrm{f}$ shells, which are well shielded (screened) from the lattice by outer shell electrons. Broad intrinsic emission generally results from self-trapped excitons (STE), which are highly localised excitons trapped by their own self-induced lattice distortion. Self-trapped excitons are generally produced in crystals with a deformable lattice (e.g., $\mathrm{SiO}_{2}$ ), which are characterised by strong electron-phonon coupling.

The emission energy of the STE is usually much lower than the band gap of the material due to energy lost by phonon emission during the electronic transition. In the present study, CL luminescence centers are dominated by $\mathrm{Dy}^{3+}$ indicated by the relatively strongest peaks at 478 491 and 573-586 $\mathrm{nm}$ in the visible light range. According to Blanc et al. [9], a weak emission line at around $630 \mathrm{~nm}$ might be assigned to $\mathrm{Gd}^{3+}$ (based on a personal communication with $\mathrm{M}$. Gaft, this peak might be related to a contamination). The weak bands at 406 and $548 \mathrm{~nm}$ might be related to $\mathrm{Tb}^{3+}[9]$.

\section{Estimation of Shock Pressure}

Gucsik et al. [10,11] were performed systematic cathodoluminescence studies of the experimentally shocked $(0,20,38,40,60,80)$ and naturally shock-metamorphosed (Ries impact crater, Germany) zircon crystals. Their results should be summarized as follows (Tables 1-4). The unshocked sample shows crosscutting, irregular fractures. The $20 \mathrm{GPa}$ sample displays some kind of mosaic texture of CL brighter and darker domains, but does not exhibit any shock metamorphic features in BSE or CL images. The 38 and $40 \mathrm{GPa}$ sample show a high density of lamellar features, which might be explained by the phase transformation between zircon- and scheelite-structure phases (reidite) of zircon and resulting differences in the energy levels of the activator elements. The CL spectra of unshocked and shocked $(20,38,40,60$ and $80 \mathrm{GPa})$ zircon samples are dominated by narrow emission lines and broad bands in the region of visible light and in the near-UV range. The emission lines result from rare earth element activators and the broad bands might be associated with lattice defects (Tables 1-3).

For all naturally shocked samples from the Ries impact crater, an inverse relationship between the brightness of the backscattered electron (BSE) signal and the corresponding cathodoluminescence intensity of the zonation patterns was observed. The CL patterns of the Stage III sample corresponds to the shock-related microstructures such as shock lamellae system (Table 4).

The widths of Planar Deformation Features (PDFs) of the shocked zircon from the Vredefort impact structure vary from 3 to $10 \mu \mathrm{m}$. This observation and data obtained by Wittmann et al. [2] and Gucsik et al. $[10,11]$ indicate a relatively high shock pressure ranging between 20-30 GPa.

Consequently, the combination of BSE and CL imaging and CL spectroscopy is a potentially useful tool that can be used to characterize the shock stage of zircons from impactites. These results also give new insight into the structural changes that occur in zircons during shock metamorphism, and the pressures associated with these changes. 
TABLE 1 Scanning Electron Microscope-Cathodoluminescence (SEM-CL) spectroseopy and microscopy of the experimentally shock-deformed zircon samples (based on [10]. Italic: broad emission bands.

\begin{tabular}{|c|c|c|}
\hline Shock Pressure (GPa) & CL Emission Bands (nm) & SEM-CL observations \\
\hline Unshocked & $314,405,485,581,631$ & $\begin{array}{l}-5 \text { to } 25 \mu \mathrm{m} \text { fractures are visible in } \\
\text { the BSE image; } \\
\text {-a distinct inverse relation between } \\
\text { BSE and CL brightness. }\end{array}$ \\
\hline 20 & $314,405,485,581,630$ & $\begin{array}{c}\text {-mosaic texture; } \\
\text {-shows irregularly distributed CL } \\
\text { bright areas (about } 10 \mu \mathrm{m} \text { ) }\end{array}$ \\
\hline 40 & $\begin{array}{c}314,353,369,387,406,419,483,548 \\
578\end{array}$ & $\begin{array}{l}\text {-a high density of well-developed } \\
\text { (CL-dark) lamellae system }\end{array}$ \\
\hline 60 & $313,407,483,578$ & $\begin{array}{l}\text {-the irregular and crosscutting } \\
\text { fractures (widths between } 5 \text { and } 50 \\
\mu \mathrm{m} \text { ), which are visible in the BSE } \\
\text { image; } \\
\text {-low CL intensity. }\end{array}$ \\
\hline
\end{tabular}

TABLE 2 Scanning Electron Microscope-Cathodoluminescence (SEM-CL) spectroscopy and microscopy of the experimentally shock-deformed zircon samples cut of parallel to their crystallographic c-axis (based on [11]. Italic: broad emission bands.

\begin{tabular}{|c|c|c|}
\hline Shock Pressure (GPa) & CL Emission Bands (nm) & SEM-CL observations \\
\hline Unshocked & $287,353,406,484,491,548,590$ & $\begin{array}{l}\text { - lack of any types of eracks or } \\
\text { fractures } \\
\text { - patchy areas of different CL } \\
\text { brightness. }\end{array}$ \\
\hline 38 & $386,406,484,491,548,590$ & $\begin{array}{c}-3-4 \mu \mathrm{m} \text { wide, curved, parallel } \\
\text { microdeformations spaced at } 5-15 \\
\mu \mathrm{m} \text { in the CL images }\end{array}$ \\
\hline 40 & $319,406,484,491,548,590$ & $\begin{array}{l}\text {-patchy areas with relatively higher } \\
\text { CL intensity, } \\
\text {-CL-dark irregular fractures }\end{array}$ \\
\hline 60 & $319,406,484,491,548,590$ & $\begin{array}{c}\text {-subplanar, } 3-8 \mu \mathrm{m} \text { wide and } 15-20 \\
\mu \mathrm{m} \text { spaced) apparently } \\
\text { crystallographically controlled, } \\
\text { lamellar microdeformations are } \\
\text { observed between the irregularly } \\
\text { shaped, cross-cutting fractures }\end{array}$ \\
\hline 80 & $319,353,406,484,491,548,590$ & $\begin{array}{l}\text {-the subplanar, widely spaced } \\
\text { (width: } 1-2 \mu \mathrm{m}, \text { spacing: } 12-15 \\
\mu \mathrm{m} \text { ), crystallographically controlled } \\
\text { microdeformations are connected } \\
\text { into the irregularly shaped, } \\
\text { crosscutting fractures }\end{array}$ \\
\hline
\end{tabular}


TABLE 3 Scanning Electron Microscope-Cathodoluminescence (SEM-CL) spectroscopy and microscopy of the experimentally shock-deformed zircon samples cut of $45^{\circ}$ to their crystallographic c-axis (based on [11]. Italic: broad emission bands.

\begin{tabular}{|c|c|c|}
\hline Shock Pressure (GPa) & CL Emission Bands (nm) & SEM-CL observations \\
\hline Unshocked & $323,406,486,491,548,590$ & $\begin{array}{c}\text {-a number of open, irregularly } \\
\text { shaped fractures in BSE mode, with } \\
\text { a great variety of widths; } \\
\text {-patchy areas of different CL } \\
\text { brightness }\end{array}$ \\
\hline 38 & $373,406,484,491,548,590,630$ & $\begin{array}{l}\text {-a high density of much closer } \\
\text { spaced, clearly crystallographically } \\
\text { controlled features }\end{array}$ \\
\hline 40 & $373,484,491,590,630$ & $\begin{array}{l}\text {-narrow, closely-spaced planar } \\
\text { microdeformation features (widths: } \\
\text { approximately } 1-2 \mu \mathrm{m} \text {; spacing: } \\
\text { approximately } 1-3 \mu \mathrm{m} \text { ) }\end{array}$ \\
\hline 60 & $373,484,491,590$ & $\begin{array}{c}\text {-subplanar, 3-8 um wide and } 15-20 \\
\mu \mathrm{m} \text { spaced) apparently } \\
\text { crystallographically controlled, } \\
\text { lamellar microdeformations are } \\
\text { observed between the irregularly } \\
\text { shaped, cross-cutting fractures }\end{array}$ \\
\hline 80 & $373,484,491,590$ & $\begin{array}{l}\text {-some areas (with relatively high } \\
\text { CL intensity) without high density } \\
\text { of irregular fractures or any types of } \\
\text { planar microdeformations }\end{array}$ \\
\hline
\end{tabular}

TABLE 4 Scanning Electron Microscope-Cathodoluminescence (SEM-CL) spectroscopy and microscopy of the naturally shock-deformed zircon samples (which were cut perpendicular and parallel to their crystallographic c-axis) from the Ries impact crater (Germany) (based on [11]. Italic: broad emission bands.

\begin{tabular}{lcc}
\hline Shock Pressure (GPa) & CL Emission Bands (nm) & SEM-CL observations \\
\hline Stage II & 406,484 (doublet:484-491) & -zonation patterns \\
Stage III & $384,406,484$ (triplet: $478-491)$, & -shock wave-related lamellar \\
& 580 & structure \\
Stage IV & $384,406,484$ (triplet: $478-491)$, & -weak CL brightness; \\
& 580 & no PDFs \\
\hline
\end{tabular}




\section{ACKNOWLEDGEMENTS}

I would like to express thank to Profs. Christian Koeberl, Eugen Libowitzky, Uwe Reimold, Franz Brandstätter supervising my Ph.D. studies at the University of Vienna, Austria and Prof Uwe Reimold providing me zircon samples from the Vredefort Dome. This chapter was partly supported by Max Planck Society at Max Planck Institute for Chemistry, Mainz, Germany.

\section{REFERENCES}

1. B. F. Bohor, W.J. Betterton, T.E. Krogh, Earth Planet. Sci. Lett.,119, 419-424 (1993).

2. A. Wittmann, T. Kenkmann, R.T. Schmitt, D Stöffler, Meteoritics Planet. Sci, 40, 1-16 (2006).

3. G. Aberg, and B. Bollmark, Earth Planet. Sci. Lett., 74, 347-349 (1985).

4. S. L. Kamo, W.U. Reimold, T.E. Krogh, W.P. Colliston, Earth Planet. Sci. Lett.,144, 369-387 (1996).

5. R. L. Gibson, R.A. Armstrong, W.U. Reimold, Geochim. Cosmochim. Acta, 61, 1531-1540 (1997).

6. W. U. Reimold, H. Leroux, R.L. Gibson, Europ. J. Mineralogy, 14, 859-868 (2002).

7. Earth Impact Database, 2009. <http:/www.unb.ca/passe/ImpactDatabase/ > (Accessed: 03/07/2009)

8. G. Remond, M.R. Phillips, C. Roques-Carmes, in: M. Pagel, V. Barbin, P. Blanc, D. Ohnenstetter (Eds.), Cathodoluminescence in Geosciences, Springer, Berlin, 2000, pp. 59-126.

9. P. Blanc, A. Baumer, F. Cesbron, D. Ohnenstetter, G. Panczer, G. Rémond, in: M. Pagel, V. Barbin, P. Blane, D. Ohnenstetter (Eds.), Cathodoluminescence in Geosciences, Springer, Berlin, 2000, pp. 127-160.

10. A. Gucsik, C. Koeberl, F. Brandstätter, W.U. Reimold, E. Libowitzky, Earth Planet. Sci. Lett, 202, 495-509 (2002)

11. A. Gucsik, C. Koeberl, F. Brandstätter, E. Libowitzky, W.U. Reimold, In: H. Dypvik, M. Burchell, and P. Claeys (Eds,) Cratering in Marine Environments and on Ice, Springer-Verlag, Heidelberg, (2004) pp 281-32 